\title{
SUSTENTABILIDADE: REFLEXÕES A PARTIR DA FRATERNIDADE E DA SOLIDARIEDADE
}

\section{SUSTAINABILITY: REFLECTIONS FROM BROTHERHOOD AND SOLIDARITY}

\author{
Mayara Pellenz ${ }^{1}$ \\ Daniela dos Santos ${ }^{2}$ \\ Ana Cristina Bacega Debastiani ${ }^{3}$ \\ Data de recebimento: 27/02/2015 \\ Data da aprovação: 10/06/2015
}

\begin{abstract}
RESUMO
O presente estudo tem como objetivo identificar a sustentabilidade sob os enfoques ético e humanístico. A humanidade encontra-se em constante cenário de crises e de riscos, sendo imprescindível que, para tentativas de superações de tais crises, reconheça seu vínculo antropológico comum. Para tanto, buscou-se discorrer sobre a fraternidade enquanto qualidade política e sobre o princípio da solidariedade previsto na Constituição da República Federativa do Brasil, como um novo "valor" a ser experimentado para se construir uma sociedade livre, justa e solidária, enfatizando, nessa conjuntura, que a concretização constitucional e o pensamento solidarista caminham juntos. Frisa-se, no contexto, a importância de se reconhecer a solidariedade conjugada com os valores de fraternidade para se chegar ao ideal de sustentabilidade, atualmente incompatíveis com o modo de relacionamento individualista e excludente do capitalismo. Esses ideais de solidariedade e de fraternidade, se vivenciados, proporcionam relações privilegiadas de experimentação política e de aplicabilidade da sustentabilidade de uma forma diferenciada, primando pela permanência da humanidade na Terra.
\end{abstract}

PALAVRAS-CHAVE: Fraternidade. Humanidade. Qualidade política. Solidariedade. Sustentabilidade.

\section{ABSTRACT}

This study aims to identify the sustainability on the ethical and humanistic approaches. Humanity is in constant crises and risks, being indispensable that, for overruns this scenario, it recognizes its common anthropological bond. Therefore, we attempted to discuss the fraternity as a political quality and the principle of solidarity found in the Constitution of the Federative Republic of Brazil, as a new "value" to be experienced to build a free, just and caring society, emphasizing, in this conjuncture, that the constitutional implementation and the supportive thought go hand. We emphasize in this context the importance of recognizing

\footnotetext{
${ }^{1}$ Mestranda do Programa de Pós Graduação em Direito da Faculdade Meridional, Especialista em Direito Penal e Direito Processual Penal pela Faculdade Meridional, Docente em Direito e advogada. E-mail: maypellenz@hotmail.com

${ }^{2}$ Mestranda em Direito, Democracia e Sustentabilidade pela IMED - Faculdade Meridional, Especialista em Direito Civil e Direito Processual Civil pela Universidade Regional Integrada-Erechim, Professora da Universidade de Passo Fundo e Advogada. E-mail: Mestranda em Direito, Democracia e Sustentabilidade pela IMED - Faculdade Meridional, Especialista em Direito Civil e Direito Processual Civil pela Universidade Regional Integrada-Erechim, Professora da Universidade de Passo Fundo e Advogada. E-mail: danielasantos@upf.br

${ }^{3}$ Mestranda do Programa de Pós Graduação em Direito da Faculdade Meridional, especialista em Direito Processual Civil pela Faculdade Anhanguera de Passo Fundo e advogada. E-mail: anacrisbacega @ hotmail.com
} 
solidarity combined with the fraternity values to reach the ideal of sustainability, currently incompatible with the individualistic and exclusive kinds of relations found in capitalism. These ideals of solidarity and brotherhood, if experienced, provide privileged relations of politic experimentation and the applicability of the sustainability in a different way, excelling for the permanence of the humankind on Earth.

KEYWORDS: Brotherhood. Humanity. Politic quality. Solidarity. Sustainability.

\section{INTRODUÇÃO}

Pretende-se, com o presente trabalho, discorrer, ainda que brevemente, sobre a fraternidade enquanto qualidade política e sobre o princípio da solidariedade como o caminho adequado para a busca da sustentabilidade, temática aqui proposta sob novo paradigma, enfatizando sua dimensão ética e humanística.

Essa dimensão será estudada sob o prisma da fraternidade e da solidariedade como valores a serem resgatados e experimentados, possibilitando assim o enfrentamento das várias crises presentes na pós-modernidade.

Dentre as várias crises mundiais postas na ordem do dia (energética, econômica, ecológica, social e humanística), conforme ensina Morin, a mais grave é a humanística, resultante do consumismo desenfreado, da globalização e da ocidentalização (2011, p. 22).

Por essa razão, idealizou-se esse estudo, com o objetivo de analisar uma nova perspectiva para a sustentabilidade, encontrando ações políticas inovadoras para assegurar a preservação da vida humana.

Assim, procurou-se analisar a fraternidade, situando-a historicamente, de forma sucinta, enquanto qualidade política. Discorreu-se também sobre o princípio da solidariedade na Constituição da República Federativa do Brasil, como um novo "valor" a ser experimentado, a fim de construir uma sociedade livre, justa e solidária, objetivo fundamental da República Federativa do Brasil, facilitando assim a posterior análise dessas relações com a sustentabilidade. A terceira e última parte está voltada para a análise da sustentabilidade, sob nova perspectiva, enfatizando suas dimensões ética e humanística, além da necessidade de se rever as relações humanas atuais.

\section{APONTAMENTOS SOBRE AS DIMENSÕES DA FRATERNIDADE}


A philia Aristotélica ${ }^{4}$ representa os primeiros ensaios de um conceito de fraternidade. Enquanto amizade é um sentimento raro, dado a algumas pessoas, a fraternidade deve ser entendida como algo mais amplo, dirigido a um número de pessoas muito maior.

O valor fraternidade foi introduzido na cultura europeia pelos cristãos, mas foram os iluministas que fundamentaram a trilogia na cultura pagã pré-cristã, devido à intensa batalha contra a Igreja e seus desmandes (BAGGIO, 2008, p. 40).

$\mathrm{Na}$ divisa da Revolução Francesa "liberdade, igualdade e fraternidade", o valor fraternidade aparece em primeiro plano, ao lado da igualdade e da liberdade; porém, diferentemente dos outros dois termos, a fraternidade não ocupou papel importante na cultura política do Ocidente (SAVAGNONE, 2009, p. 195).

Sabe-se que foi o aspecto ideológico da Revolução Francesa que eliminou a alma religiosa, distorcendo os três princípios por ela proclamados, dificultado principalmente a concretização da fraternidade. Assim, a fraternidade foi relegada, sendo endereçada apenas aos concidadãos, contribuindo na educação das crianças e como reforço para a união dentro do Estado (BAGGIO, 2008, p. 40). Enquanto a igualdade e a liberdade foram amplamente discutidas e aceitas como categorias políticas, a fraternidade foi silenciada e deslocada a campos fora dela.

Alguns autores, como Alexis Tocqueville ${ }^{5}$, afirmaram que a França não obteve os resultados da Revolução Americana exatamente por ter deixado de lado as motivações religiosas impregnadas na fraternidade. A liberdade e a igualdade não conseguiram alçar seus voos devido à privação desse anseio religioso, pois foi o espírito religioso que fez com que a democracia norte-americana superasse os vícios fundamentais dos homens, moderando sua agressividade e a sua rudeza (PEZZIMENTI, 2008, p. 62).

Porém, não se pode vincular a secularização e a perda das raízes religiosas como a única responsável pelo "esquecimento" da fraternidade, uma vez que, ao longo dos séculos, mesmo tendo raízes teológicas fortes, isso não impediu a criação de sociedades altamente hierarquizadas, súditos com mais deveres do que direitos, guerras e escravidão.

\footnotetext{
${ }^{4} \mathrm{O}$ conceito aristotélico de amizade é bastante amplo, uma vez que abarca a utilidade, o prazer, o bem e a amizade entre os desiguais. Em todos os tipos de amizade por ele propostos fica clara a exigência da reciprocidade, pois sem ela não será possível falar-se em amizade. No entanto, para o trabalho que está sendo desenvolvido, o mais importante é a amizade enquanto qualidade política. O homem é um ser político e viver em comunidade o torna assim. Daí que a amizade enquanto qualidade política deve ser vista como uma forma a possibilitar novos sujeitos sociais, novos modos de existir e de conviver (ARISTÓTELES, 1999, p. 153).

${ }_{5}^{5}$ Alexis de Tocqueville, além de ser o autor do famoso estudo "A democracia na América, também foi o autor de L'ancien régime et la Révolution, obra sobre a Revolução Francesa, que por muito tempo permaneceu desconhecida (PEZZIMENTI, 2008, p. 59).
} 
A fraternidade, apesar de ter origens antigas e religiosas, deve ser reestruturada no mundo contemporâneo. Isso quer dizer ser entendida como um princípio/valor norteador da liberdade e da igualdade, implicando assim um primeiro passo à cidadania (IGHINA, 2009, p. $35)$.

Ensina Domingo Ighina que "a fraternidade leva em seu seio a consciência da liberdade e o direito da igualdade"; o contrário traduz a linha da exclusão e da opressão. Assim, o princípio da fraternidade tem o condão de articular o princípio da liberdade (liberdade política) e o da igualdade como justiça social (2009, p. 35).

O conceito de cidadania é claramente visualizado na Antiguidade Clássica e na Idade Média. No caso das pólis gregas, por exemplo, os cidadãos eram livres e iguais (eleutheroi kai ísoi), governavam e eram governados (em rodízio), e formavam as leis que eram para todos de forma igual (isegoria e isonomia), demonstrando claramente governos democráticos (TOSI, 2009, p. 48). Mesmo que essa cidadania fosse restrita (somente aos cidadãos livres), o sistema de democracia participativa da pólis grega, sobretudo da ateniense, foi considerado perfeito e até hoje não se encontrou na história da humanidade modelo parecido (TOSI, 2009, p. 49).

No entanto, foram os estóicos que, no período de transição da pólis grega à Cosmópolis do império helenístico e romano, trouxeram um novo modelo, a comunidade civil mundial (universalismo), composta por deuses e pelos homens e comandada pela lei natural. $\mathrm{Na}$ cidade universal tudo estaria subordinado ao bem superior do universo; sendo assim, tanto os escravos quanto os bárbaros foram considerados iguais e livres enquanto seres humanos pelo princípio do amor universal (phília). Foi Zeus quem promulgou essa lei, não podendo ser abolida nem pelo Senado nem pelo povo, pois o seu não cumprimento não era considerado apenas uma negação do mandamento divino, mas sim da própria natureza do homem (TOSI, 2009, p. 49). E, ao que parece, a fraternidade foi abarcada por tal lei:

Constitui-se, assim, sobre tal lei uma comunidade natural, que compreende tanto os homens quanto os deuses, que devem obedecer a uma lei comum, manifestada na propensão natural do homem a amar seus semelhantes; não somente seus concidadãos, mas todos os homens, enquanto cidadão de uma mesma república de que Zeus é o senhor (TOSI, 2009, p. 49). 
No cristianismo, esse conceito é ainda mais forte e claro: "em nome da fraternidade universal, sem distinção entre bárbaros ou gregos, judeus ou romanos, escravos ou livres" (TOSI, 2009, p. 50).

Contudo, apesar de estar bem colocada, a fraternidade não conseguiu se consagrar como valor ético, político e religioso na modernidade, princípio norteador da liberdade e da igualdade. E nem os esforços normativos o conseguiram, como sua invocação, em 1948, no preâmbulo da Declaração Universal dos Direitos do Homem, em relação à obrigação que todas as pessoas têm de "agir em relação umas às outras com espírito de fraternidade", e em muitas Constituições, como no caso da brasileira atual, que a invoca já no seu preâmbulo (BUONOMO, 2009, p. 169):

\begin{abstract}
Nós, representantes do povo brasileiro, reunidos em Assembleia Nacional Constituinte para instituir um Estado Democrático, destinado a assegurar o exercício dos direitos sociais e individuais, a liberdade, a segurança, o bemestar, o desenvolvimento, a igualdade e a justiça como valores supremos de uma sociedade fraterna (grifos nossos), pluralista e sem preconceitos, fundada na harmonia social e comprometida, na ordem interna e internacional, com a solução pacífica das controvérsias, promulgamos, sob a proteção de Deus, a seguinte CONSTITUIÇÃO DA REPUBLICA FEDERATIVA DO BRASIL (BRASIL, 1988).
\end{abstract}

Pior, o desenvolvimento a qualquer custo e o progresso tecnológico da pósmodernidade acentuaram aspectos individualistas e egoístas da humanidade, fazendo com que o caráter social, fraterno e solidário fosse relegado e até mesmo esquecido.

Daí que Morin (2011, p. 22) salienta que, sem uma reflexão e uma nova consciência sobre o mundo globalizado e os modelos de sociedades, dificilmente se conseguirá enfrentar as crises da pós-modernidade que assolam a humanidade. Segundo o autor, faz-se necessária uma metamorfose, uma mudança na concepção de mundo pela conscientização.

Essa conscientização nada mais é do que uma consciência comum de humanidade, consciência bem posta pela Declaração Universal, em seu artigo 29, onde predominaram os interesses gerais sobre os interesses particulares. Prevê tal artigo que "todo ser humano tem deveres para com a comunidade, na qual, unicamente, o livre e pleno desenvolvimento de sua personalidade é possível” (BUONOMO, 2009, p. 170).

Baggio (2009, p. 85) vai além, para quem a "ideia de fraternidade é o da participação democrática, ou seja, da conexão da ideia de fraternidade com a de cidadania” (grifos nossos), 
e conclui que foi a fraternidade a responsável pela efetiva construção de novas identidades de povos, conforme vários exemplos históricos, evidenciando assim sua dimensão política.

A fraternidade é condição humana: somente ela é capaz de fomentar a ideia de uma comunidade universal, onde as pessoas, indiferentemente de onde vivam e a que povos pertençam, consigam viver em paz (BAGGIO, 2008, p. 53-54).

A igualdade e a liberdade tornam-se vazias sem a fraternidade. Explica-se: se vivida fraternalmente, a liberdade não se torna vontade do mais forte, assim como a igualdade não degenera em igualitarismo impiedoso (BAGGIO, 2008, p. 54).

Segundo Morin (2011, p. 43), cabe a arte da política a missão de alcançar um ideal humano de liberdade, igualdade e fraternidade. Essa é a via para a salvação. E salienta que essa nova política deverá obedecer a uma dupla orientação: uma política de humanidade e uma política de civilização, no sentido de restaurar a fraternidade e, dessa forma, reumanizar as cidades.

Portanto, para a continuidade da própria humanidade, faz-se necessário recuperar a categoria da fraternidade, tanto no âmbito religioso que prega que "todos os homens são iguais e livres porque são irmãos" (BAGGIO, 2008, p. 53), quanto na dimensão política, fazendo com que a humanidade retire as vestes da individualidade e em sua nudez se reinvente, corroborando para fortalecer o vínculo antropológico comum.

\section{PRINCÍPIO DA SOLIDARIEDADE NA CONSTITUIÇÃO DA REPÚBLICA FEDERATIVA DO BRASIL}

O Estado liberal triunfou até a metade do século XIX, tendo como protagonista o individualismo exacerbado; porém, no fim do século XIX e início do século XX, a ideia de solidariedade foi lançada por filósofos, sociólogos e juristas (FARIAS, 1998, p. 187), criando um novo tipo de relacionamento entre as pessoas, modificando a relação indivíduo-sociedadeindivíduo-Estado, traçando as primeiras linhas do aclamado Estado Social.

Diz-se que foi o valor fraternidade que inspirou a solidariedade e que esta teve sua origem no estoicismo e no cristianismo primitivo. Apenas no fim do século XIX é que aparece a lógica da solidariedade com um discurso coerente, distanciando-se da "caridade" ou "filantropia" (FARIAS, 1998, p. 190).

A modernidade trouxe a necessidade de revelar ao homem que, diferente do conceito liberal-individualista que até então o mesmo festejava (onde o indivíduo é uma pequena 
"totalidade", uma microcélula autônoma, autossuficiente e autossubsistente), é possuidor de um destino singular e faz parte da comunidade humana. Sendo assim, não pôde mais ser estimado e sua relação com os semelhantes passou a ser constitutiva de sua existência (MORAES, 2011). "Quem habita este planeta não é o homem, mas os homens. Pluralidade é a lei da terra" (ARENDT apud MORAES, 2011, p. 03). Logo, a solidariedade deve ser vista como fato social, pois só se concebe o indivíduo inserido em sua comunidade.

Ser solidário é partilhar, ao menos, uma mesma época e, neste sentido, uma mesma história, sendo a solidariedade, de fato, objetiva, quando permite distinguir "uma sociedade de uma multidão" (MORAES, 2011, p. 4).

Afirma Moraes (2011, p. 7) que a solidariedade apresenta diversas facetas:

[...] como um fato social do qual não podemos nos desprender, pois é parte intrínseca do nosso ser no mundo; como virtude ética de um reconhecer-se no outro (que "faz do outro um outro eu próprio") ainda mais amplo do que a justa conduta exigiria (dar ao outro o que é seu); como resultado de uma consciência moral e de boa-fé ou, ao contrário, de uma associação para delinquir; como comportamento pragmático para evitar perdas pessoais e/ou institucionais. Fato social, virtude, vício, pragmatismo e norma jurídica são os diferentes significados do termo.

Foi em meados de 1919 que Rui Barbosa negou o individualismo jurídico, reconhecendo a "superioridade do trabalho sobre o capital...", defendendo um grande programa envolvendo questões sociais. Cabe salientar que, no campo da teoria do direito, o discurso solidarista no Brasil teve como protagonistas Rui Barbosa, Tobias Barreto e Joaquim Nabuco (FARIAS, 1998, p. 191-192).

Em sua obra Teoria Política, afirma Rui Barbosa (apud FARIAS, 1998, p. 192):

A concepção individualista dos direitos humanos tem evoluído rapidamente, com os tremendos sucessos deste século, para a transformação incomensurável nas noções jurídicas do individualismo restringidas agora por uma extensão, cada vez maior, dos direitos sociais. Já se não vê na 
sociedade um mero agregado, uma justaposição de unidades individuais, acasteladas cada qual no seu direito intratável, mas uma entidade naturalmente orgânica, em que a esfera do individualismo tem por limites inevitáveis, de todos os lados, a coletividade. O direito vai cedendo à moral, o indivíduo à associação, o egoísmo à solidariedade humana.

Igualmente na tríade da Revolução Francesa, onde a fraternidade foi relegada, a solidariedade tornou-se um mito na contemporaneidade. Afirma Farias (1998, p. 194) que a "palavra solidariedade torna-se uma espécie de fantasma na memória do homem contemporâneo, servindo para dar boa consciência a uns e amenizar a má consciência de outros".

Foi com a promulgação da Constituição da República Federativa do Brasil, em 1988, que a solidariedade tomou corpo de princípio. O constituinte, ao estatuir os objetivos fundamentais da República Federativa do Brasil, em seu artigo 3, I, estabeleceu, entre outros fins, a construção de uma sociedade livre, justa e solidária.

A esse objetivo o legislador elencou outros, previstos nos demais incisos do referido artigo: II- garantir o desenvolvimento nacional; III- erradicar a pobreza e a marginalização e reduzir as desigualdades sociais e regionais; IV - promover o bem de todos, sem preconceitos de origem, raça, sexo, cor, idade e quaisquer outras formas de discriminação.

Realizando uma análise superficial do que fora posto, constata-se que o constituinte traçou metas no sentido de dar efetividade aos objetivos elencados, deixando clara a necessidade da correção das desigualdades sociais e regionais através da erradicação da pobreza e da marginalização, promovendo dessa forma o desenvolvimento econômico e social, e por meio da solidariedade melhorar a qualidade de vida de seus cidadãos.

Ainda, pode-se afirmar que o constituinte de 1988, ao se referir à solidariedade (como objetivo fundamental da República Federativa Brasileira), demonstrou claramente sua preocupação com a atuação Estatal e a inclusão da sociedade nessa atuação, tanto no momento da elaboração da legislação ordinária (Poder Legislativo), na execução das políticas públicas (Poder Executivo), como na interpretação-aplicação do Direito (Poder Judiciário e operadores).

Também é possível visualizar os efeitos da solidarização constitucional nos demais ramos do direito: no Direito Civil, o direito à propriedade versus a função social; no campo contratual, o enfoque não é mais voluntarista, buscando-se o equilíbrio entre as partes contratantes bem como a vedação da excessiva onerosidade; nas relações familiares, a exclusão das rígidas hierarquizações, traçando novas concepções, como a igualdade entre os 
cônjuges, igualdade entre os filhos, prevalência do melhor interesse da criança e do adolescente, guarda compartilhada (MORAES, 2011, p. 12).

Nesse viés, a doutrina e a jurisprudência citam como o corolário da tendência solidarista a criação da seguridade social, tendo como postulado a "Solidariedade Financeira ${ }^{6}$, , conforme artigo 195 da Constituição Federal de 1988. Os tribunais brasileiros não tardaram a reconhecer a solidariedade constitucional como o "dever jurídico de respeito, de âmbito coletivo, cujo objetivo visa beneficiar a sociedade como um todo" (MORAES, 2011, p. 12-13). Prova disso é a vasta jurisprudência do Supremo Tribunal Federal nesse sentido $^{7}$.

No seu projeto solidarista, além das normas que indiretamente afrontam tais desigualdades, também teve o legislador a preocupação com a destinação de recursos para tal fim. Exemplo dessa preocupação foi a mudança do texto constitucional através da Emenda Constitucional 31, de 14 de dezembro de 2000, que criou o "Fundo de Combate e Erradicação da Pobreza", salientando que seus recursos deverão ser utilizados em ações suplementares de nutrição, habitação, educação, saúde, reforço da renda familiar e programas de relevante interesse social voltados para a melhoria da qualidade de vida (MORAES, 2011, p. 15).

Portanto, o legislador constituinte apoiou-se nos princípios da dignidade da pessoa humana e da solidariedade social, entendendo serem estes imprescindíveis para o enfrentamento das desigualdades concretas do contexto da sociedade brasileira.

O princípio da solidariedade introduziu na ordem jurídica uma nova ideologia baseada no princípio da dignidade humana, principalmente nas questões relativas à qualidade de vida das pessoas, fazendo que os direitos fundamentais de terceira dimensão se desligassem do homem-indivíduo, assumindo assim uma conotação difusa. Talvez por isso haja tanta dificuldade do homem como ser individual se conscientizar e reconhecer os direitos em sua pluralidade (CARDOSO, 2010, p. 25).

\footnotetext{
${ }^{6}$ A Solidariedade Financeira é financiada direta ou indiretamente por toda a sociedade, uma vez ser responsável pelo destino de seus membros. (MORAES, 2011, p. 12).

${ }^{7}$ Exemplos da aplicação do princípio da solidariedade pelo Supremo Tribunal Federal: STF, Tribunal Pleno, MS n 22.164-0/SP, Rel. Min. Celso de Mello, j. Em 20/10/1995, Ement. Vol. 01809-05, p. 1.155, v.u. - STF, Tribunal Pleno, ADI n 240/RJ, Rel. Min. Octavio Gallotti, j. em 26/9/1996, DJ de 13/10/2000, v.u. - STF, Tribunal Pleno, ADIMC n 1003/DF, Rel. Min. Celso de Mello, j. Em 1/8/1994, DJ de 10/9/1999, v.u. - STF, Tribunal Pleno, ADI n 1856/RJ, Rel. Min. Celso de Mello, j. Em 26/05/2011, DJ de 14/10/2011, v.u.
} 
Diante das novas exigências fundamentais do ser humano nascem os direitos de terceira dimensão, propiciando um novo olhar, vindo a superar a exclusividade da tutela estatal, uma vez que é imprescindível a união de esforços para a construção de um mundo menos desigual. Ilustrando bem esse quadro leciona Cardoso (2010, p. 26-27):

Com certeza, os direitos fundamentais de terceira dimensão são aquilo que uma "sociedade justa" mais aspira para seus membros, e seu mérito principal, além de formatar um plano ético para o direito, é a superação dos primados privado e público pelo reconhecimento dos interesses sociais. Em que pesem os avanços alcançados pelas dimensões anteriores, o fato é que tanto a sociedade quanto o Estado continuam a se mostrar indiferentes ao sofrimento causado pela liberdade econômica, advindo daí o valor da solidariedade como único meio capaz de realizar a dignidade da pessoa humana como gênero e em a toda sua plenitude.

A sociedade contemporânea passa por um estado doentio, a moral passa por uma crise terrível. Diante dessas afirmações, Cardoso (2010, p. 104-105) traduz a sociedade contemporânea e suas banalizações diante das misérias humanas: "a civilização humana chegou num estágio em que seu elemento central perdeu o significado", e soluciona dizendo que será somente pelo reconhecimento dos direitos do próximo que o ser humano possibilitará à sociedade um ambiente propício à justiça e à segurança, e que o caminho mais adequado é através da solidariedade.

Portanto, é imprescindível a renúncia ao modo exclusivista do direito individual, sendo indispensável uma conscientização da realidade social em que está inserido, construindo através do exercício da solidariedade o esperado direito social, possibilitando, dessa forma, a efetivação dos direitos fundamentais.

\section{A CONSTRUÇÃO DA SUSTENTABILIDADE SOCIAL: EM BUSCA DE CAMINHOS FRATERNOS E SOLIDÁRIOS}

O paradigma da sustentabilidade está no desafio de a humanidade adequar suas condutas a um desenvolvimento coletivo, em que seja possível a conservação do meio ambiente e a construção de uma sociedade mais justa, solidária e humana. Portanto, em que 
medida a fraternidade e a solidariedade podem contribuir para a construção e a efetividade da sustentabilidade social?

Freitas (2012, p. 49), ao propor um conceito de princípio da sustentabilidade, afirma que é primordial estar incluído no mesmo a faceta multidimensional de bem-estar. Conforme esse autor:

[...] é o princípio constitucional que determina, com eficácia direta e imediata, a responsabilidade do Estado e da sociedade pela concretização solidária do desenvolvimento material e imaterial, socialmente inclusivo, durável e equânime, ambientalmente limpo, inovador, ético e eficiente, no intuito de assegurar, preferencialmente de modo preventivo e precavido, no presente e no futuro, o direito ao bem-estar (2012, p. 50).

Observa-se em tal conceito, primeiramente, que o autor defende que a responsabilidade não seja exclusiva do Estado, impondo à sociedade também esse dever, sem novidades, uma vez que é a própria Constituição de 1988 que, no Brasil, assim prevê o direito fundamental ao meio ambiente ${ }^{8}$ como um dever e um princípio, ao mesmo tempo, estando o dever de sua guarda e de sua promoção/proteção distribuído por toda a coletividade. Da divisão coletiva dessas responsabilidades, obviamente exsurge o caráter solidário das vias a serem usadas para a sua concretização, ou seja: esse compartilhamento somente será possível se as pessoas utilizarem-se de sua racionalidade de forma fraterna e solidária.

Afirma Freitas (2012, p. 44) que a humanidade corre grande risco de extinção, devido ao grande crescimento econômico sem nenhum respeito ao meio ambiente sadio, cenário no qual o homem vem provocando danos irreparáveis. Diante disso, chegou a hora de a humanidade começar a exercer outro papel, deixando de lado seu espírito destruidor e dominador, assumindo uma postura ética, para "salvar a humanidade dela mesma, enquanto é tempo".

Seria temerário acreditar que a humanidade irá deixar de lado todos os benefícios que a globalização ou a mundialização trouxe em detrimento dos malefícios que também veio

\footnotetext{
${ }^{8}$ Art. 225. Todos têm direito ao meio ambiente ecologicamente equilibrado, bem de uso comum do povo e essencial à sadia qualidade de vida, impondo-se ao Poder Público e à coletividade o dever de defendê-lo e preservá-lo para as presentes e futuras gerações (BRASIL, 1988).
} 
gerando em paralelo, mas é imprescindível que se encontrem formas de conciliar a tecnologia com a modernização ecológica (FREITAS, 2012, p. 46).

Por certo que o desenvolvimento, por si só, não há de ser contraditório em relação à sustentabilidade. Mas essa relação precisa se entendida de forma correta, pois a sustentabilidade consistiria em assegurar o bem-estar próprio e alheio, material e imaterial, para as presentes e futuras gerações. Assim, faz-se necessária a utilização de indicadores avançados, como o índice de Desenvolvimento Humano, que mede renda, longevidade e educação (FREITAS, 2012, p. 42-43).

Para Ferrer (2012, p. 311), há clara necessidade da busca pela harmonia em todos os setores da vida humana, como um fio condutor para o esperado e adequado progresso tão almejado pela sociedade. Ao se pensar em qualidade de vida, por exemplo, além dos elementos básicos como a riqueza e o emprego, é importante levar outros elementos em consideração, uma vez que os indivíduos necessitam ter a certeza de pertença a seu grupo social. Para que isso seja possível, é imprescindível repensar a forma pela qual o Direito atual está fundamentado: na dominação.

Conforme defende Ferrer (2012, p. 312-313), o Direito é produto cultural, reflete as crenças e valores daquele grupo social. A relação do homem com a natureza, com o meio em que vive, sempre foi de dominação. Essa relação precisa ser modificada, caso contrário, o homem corre o risco de ele próprio se extinguir. O autor (2012, p. 314) destaca ainda que a estrutura clássica do Direito, tal qual está posta, somente se modificará por meio de uma revolução ambiental, que não se encontra no campo tecnológico, mas sim no cultural.

Nessa temática, um dos grandes equívocos da humanidade é pensar que está acima da natureza, e que esta deve servi-lo. Porém, aos poucos, o homem está tomando consciência da necessidade de mudanças para assegurar a sua própria subsistência no Planeta Terra.

Exemplos desta nova forma de pensamento foram as quatro "ondas" - Conferências das Nações Unidas sobre Meio Ambiente, que ocorreram em 1972, 1992, 2002 e 2012. Estas conferências possibilitaram grandes avanços científicos e jurídicos, bem como a proliferação de legislações ambientais. Foram tomadas posturas frente às agressões que o Planeta vem sofrendo, estabeleceram-se limites ao crescimento econômico e à constitucionalização do direito ambiental em muitos países.

Além da Declaração do Rio, adotou-se a Agenda XXI, aprovou-se o Convênio sobre a Diversidade Biológica e o Convênio Marco sobre mudança climática, mas as discussões foram mais longe, abordando a necessidade do desenvolvimento e da erradicação da pobreza, a titularidade dos recursos naturais e o controle da ciência e da tecnologia (FERRER, 2012, p. 
314-319). Não há como negar que se avançou nessas discussões, porém o caminho para se alcançar a sustentabilidade está muito aquém do esperado, seja por razões econômicas, sociais ou por interesses que vão além das necessidades globais e humanas.

Nesse sentido, Ferrer (2012, p. 319) afirma que o grande paradigma da humanidade é a sustentabilidade, a vontade de construir uma nova sociedade capaz de perpetuar-se no tempo e em condições dignas. A deterioração do planeta é insustentável (aquecimento global, poluição do ar e escassez de água), mas a miséria, a fome, as desigualdades de renda, a exclusão social, as injustiças, a opressão, a violência, o preconceito e o individualismo, bem como a escravidão e a dominação cultural e econômica também são condições insustentáveis, que estão afetando não só o meio ambiente, mas a humanidade, como um todo.

Por isso mesmo, a resposta para essas crises está num conceito mais amplo e global, um conceito que favoreça a integração e a inclusão das pessoas e as estimule a participar das decisões globais com responsabilidade, em que todos tenham a consciência de que pertencem a um todo e que compartilhem suas responsabilidades para a manutenção da vida humana e do planeta (FERRER, 2012, p. 324).

Assim, para que se busque uma sociedade sustentável, primeiramente precisa-se de cidadãos solidários. São cidadãos conscientes de seus desafios no mundo atual, que reconheçam a si e aos demais como sujeitos com dignidade, conheçam seus direitos e suas obrigações, não admitam as injustiças e não compactuem com qualquer desrespeito aos direitos humanos, respeitam e valorizem as diferenças, tanto de gênero, de identidade e de culturas como fonte de enriquecimento humano, enfim, se interessem, se comprometam, participem e contribuam para criar uma cidadania ativa e coletiva, a fim de combater as desigualdades através da busca da redistribuição do poder, das oportunidades e dos recursos (FERRER, 2012, p. 324).

Contrariamente a esses conceitos, o que se vê hoje é uma a sociedade individualista, apática, que desfruta dos prazeres do presente desenfreadamente, uma vez que o futuro é incerto e nem se sabe se irá acontecer. As relações humanas estão fundamentadas na fugacidade e na futilidade, cultuadas por pessoas escravas do consumo, dos produtos e da tecnologia.

A incessante busca da aceitação social, com a banalização do "ser" em detrimento ao culto do "ter", fazem com que as sociedades modernas lutem diariamente contra a ruína do ser humano. O consumo desenfreado é intenso, fazendo com que os produtos se tornem ultrapassados instantaneamente. Sendo assim, as pessoas procuram demasiadamente coisas/objetos que as façam felizes, acreditando que a felicidade é a liberdade de consumo 
ligada à propriedade (capacidade de adquirir). Porém, essas condutas não resultam em mais felicidade e liberdade, mas antes traduzem os conflitos e a falta de confiança entre os integrantes dessa mesma sociedade (BAUMAN, 2011, p. 121).

Dessa forma, a lição de Bauman é a de que a assim por ele denominada "liberdade líquida" exclui aqueles cujos comportamentos consumistas são falhos, sendo esses eliminados do "jogo", transformando o ser humano em mero objeto; esses comportamentos fortalecem o individualismo, opondo-se ao coletivo (2011, p. 142). Ora, a sociedade feita dessas regras se desfaz a todo o momento para ter coisas novas, ou seja, se desfaz do antigo self para constituir um novo, para estar apto a jogar as regras mercantis de convivência posta. Mas como se desfazer e se refazer sem causar danos colaterais? - indaga Bauman (2011, p. 141).

E ele mesmo ensina que esse refazer será possível resgatando valores justamente de solidariedade (valor/fraternidade), dentro de um Estado Social em que o ser humano tenha mais valor do que as coisas, sendo portador de um sentimento de respeito diante da sociedade em que vive, protegendo o meio ambiente, as relações com os demais, resgatando a confiança e, assim, garantindo a convivência coletiva (BAUMAN, 2011, p. 148).

Nessa linha de pensamento, salienta Morin (2011, p. 22) que sem uma reflexão e uma nova consciência sobre o mundo globalizado e os modelos de sociedades dificilmente se conseguirá enfrentar as crises atuais. Para esse autor, diante da globalização, versão atualizada da mundialização, a cultura do capitalismo dissemina pelo mundo sua forma, e juntamente com o consumismo desenfreado, o lucro a qualquer custo, aliados aos interesses dos blocos econômicos, o mundo encontra-se em múltiplas crises (energética, econômica, ecológica, social e humanística), o que vem impedindo a formação de uma consciência comunitária compartilhada (MORIN, 2011, p. 20-22).

Freitas (2012, p. 24) também alerta que devido a essa cultura da insaciabilidade patrimonialista e senhorial, que não se satisfaz nunca e com nada, é a primeira vez na História (salvo risco de guerra nuclear) que a humanidade está inviabilizando a sua permanência na terra. Por isso, além das dimensões social, ambiental e econômica, clássicas da sustentabilidade, há urgência em assimilar também a dimensão jurídico-política e ética, e traça um diagnóstico: "para avançar a bandeira da sustentabilidade, vários muros mentais terão que cair" (FREITAS, 2012, p. 25).

E completa afirmando que a sociedade do conhecimento terá que se tornar a do autoconhecimento, voltada ao bem-estar universalizado. Somente assim será possível fazer frente às múltiplas crises, embora diga que o remédio sempre traz o risco dos efeitos colaterais (FREITAS, 2012, p. 26). 
Portanto, é preciso que seja realizado um trabalho de equipe por todos os atores da sociedade, criando espaços de diálogo, incentivando atitudes ecologicamente corretas, uma sociedade menos consumidora e mais preocupada com seu vínculo antropológico comum.

É imprescindível para a sustentabilidade como fator ético e humanístico que se enxergue o outro como eu e o universo como lar (terra pátria), criando-se condições propícias para uma vida sustentável. A sustentabilidade deve ser vista como um fenômeno humano, sendo imperativa a sua preservação. A chave da mudança está no pensamento de uma política global de sustentabilidade, que promova formas fraternas, solidárias e educacionais para condutas humanas mais sustentáveis.

Por fim, para que o desenvolvimento sustentável seja algo palpável, é imperativo que se tenha consciência do que une os seres humanos, de seu vínculo antropológico comum e que o princípio da solidariedade seja ressuscitado e se instale efetivamente no terreno jurídico, convertendo a humanidade em um grupo único, promovendo assim o tão almejado Estado Social.

\section{CONSIDERAÇÕES FINAIS}

Na sociedade contemporânea, cada vez mais as relações estão pautadas pelo impedimento da palavra e pelas exclusões sociais, fazendo com que os laços de fraternidade e solidariedade se enfraqueçam. Os sujeitos encontram-se cada vez mais isolados e o individualismo vem imperando, sendo necessário resgatar ideais de fraternidade e solidariedade, revelando modos mais humanos e justos de enfrentamento das desigualdades sociais, da degradação do meio ambiente, da exclusão e da opressão.

É por meio da experimentação do valor/fraternidade e da solidariedade que a humanidade criará vínculos, repletos de trocas de conhecimentos e aprendizagens, nos quais será possível modificar e potencializar suas habilidades, além de aguçar sonhos ainda não realizados, como uma vida mais humana e sustentável. Dessa forma, a vida humana se viabilizará, uma vez que a sustentabilidade não deve ser encarada apenas pelo viés ambiental, mas também como um instrumento para a humanização, não só das relações interpessoais, mas de todas as formas de vida. 
A humanidade precisa rever sua forma de viver e conviver tanto com seus semelhantes como com a Natureza. O valor/fraternidade e a solidariedade são caminhos a serem (re)visitados e (re)experimentados, propiciando dessa forma espaços a experiências genuinamente humanas. O Direito se resume em conflitos entre humanos e as normas, por si mesmas, são meras aspirações. Logo, novas conquistas serão possíveis com a participação de todos, uma vez que pertencem àquele momento histórico e social que combate o esmorecimento político, a fragilidade dos laços humanos, e luta contra as condições subhumanas a que algumas pessoas são submetidas, seja pelo seu trabalho, pela sua cor, pela sua opção sexual ou religiosa, entre outras, fazendo com que as pessoas se articulem e se comprometam coletivamente para a construção de uma sociedade mais fraterna, solidária e justa.

\section{REFERÊNCIAS}

ARISTÓTELES. Ética a Nicômacos. Tradução de Mário da Gama Cury. 3. ed. Brasília: UNB, c1985, 1999, p. 17-111. Título original: Ethikon Nikomacheion.

BAGGIO, Antônio Maria. A ideia de fraternidade em duas Revoluções: Paris 1789 e Haiti 1791. In: BAGGIO, Antônio Maria (Org.). O principio esquecido/1. Vargem Grande Paulista, SP: Cidade Nova, 2008. p. 07-55.

A inteligência fraterna. Democracia e participação na era dos fragmentos. In: p. 85-130. (Org.). O principio esquecido/2. Vargem Grande Paulista, SP: Cidade Nova, 2009.

BAUMAN, Zygmunt. A ética é possível num mundo de consumidores. Tradução de Alexandre Werneck. Rio de Janeiro: Zahar, 2011.

BRASIL. Constituição República Federativa do Brasil. Promulgada em 5 de outubro de 1988, atualizada até a emenda constitucional $\mathrm{n}^{\circ}$ 75. Disponível em: <http://www.planalto.gov.br/ccivil_03/constituicao/constituicaocompilado.htm>. Acesso em: 21 mar. 2014.

Supremo Tribunal Federal. Tribunal Pleno, MS n 22.164-0/SP, Rel. Min. Celso de Mello, j. Em 20/10/1995, Ement. Vol. 01809-05, p. 1.155, v.u. Disponível em: $<$ http://www.stf.jus.br/portal/jurisprudencia/listarJurisprudencia.asp?s1=\%28princ\%EDpio+d a+solidariedade $\% 29+\% 28 \% 28 \mathrm{CELSO}+\mathrm{DE}+\mathrm{MELLO} \% 29 \% 2 \mathrm{ENORL} \% 2 \mathrm{E}+\mathrm{OU}+\% 28 \mathrm{CELSO}$ + DE + MELLO $\% 29 \% 2 \mathrm{ENORV} \% 2 \mathrm{E}+\mathrm{OU}+\% 28 \mathrm{CELSO}+\mathrm{DE}+\mathrm{MELLO} \% 29 \% 2 \mathrm{ENORA} \% 2 \mathrm{E}+\mathrm{O}$ U+\%28CELSO+DE+MELLO \%29\%2EACMS\%2E\%29\&base=baseAcordaos\&url=http://tiny url.com/nd3ho2a. Acesso em: 24 mar. 2014. 
Supremo Tribunal Federal. Tribunal Pleno, ADI n 240/RJ, Rel. Min. Octavio Gallotti, j. em 26/9/1996, DJ de 13/10/2000, v.u. Disponível em: http://www.stf.jus.br/portal/jurisprudencia/listarJurisprudencia.asp?s1=\%28Octavio+Gallotti \%29\%28240\%2ENUME\%2E+OU+240\%2EACMS\%2E\%29\&base=baseAcordaos\&url=http: //tinyurl.com/pjm7nbh. Acesso em: 24 mar. 2014.

. Supremo Tribunal Federal. Tribunal Pleno, ADIMC n 1003/DF, Rel. Min. Celso de Mello, j. Em 1/8/1994, DJ de 10/9/1999, v.u. Disponível em: $<$ http://www.stf.jus.br/portal/jurisprudencia/listarJurisprudencia.asp?s1=\%28princ\%EDpio+d a+solidariedade\%29+\%28\%28CELSO+DE+MELLO\%29\%2ENORL\%2E+OU+\%28CELSO +DE+MELLO \% 29\%2ENORV\%2E+OU+\% 28CELSO+DE+MELLO \% 29\%2ENORA\%2E+O U+\%28CELSO+DE+MELLO \%29\%2EACMS\%2E\%29\&base=baseAcordaos\&url=http://tiny url.com/nd3ho2a. Acesso em: 24 mar. 2014.

. Supremo Tribunal Federal. Tribunal Pleno, ADI n 1856/RJ, Rel. Min. Celso de Mello, j. Em 26/05/2011, DJ de 14/10/2011, v.u. Disponível em: $<$ http://www.stf.jus.br/portal/jurisprudencia/listarJurisprudencia.asp?s1=\%28princ\%EDpio+d a+solidariedade $\% 29+\% 28 \% 28 \mathrm{CELSO}+\mathrm{DE}+\mathrm{MELLO} \% 29 \% 2 \mathrm{ENORL} \% 2 \mathrm{E}+\mathrm{OU}+\%$ 28CELSO $+\mathrm{DE}+\mathrm{MELLO} \% 29 \% 2 \mathrm{ENORV} \% 2 \mathrm{E}+\mathrm{OU}+\% 28 \mathrm{CELSO}+\mathrm{DE}+\mathrm{MELLO} \% 29 \% 2 \mathrm{ENORA} \% 2 \mathrm{E}+\mathrm{O}$ U+\%28CELSO+DE+MELLO \%29\%2EACMS\%2E\%29\&base=baseAcordaos\&url=http://tiny url.com/nd3ho2a. Acesso em: 24 mar. 2014.

BUONOMO, Vincenzo. Vínculos relacionais e modelo de fraternidade no direito da Comunidade Internacional. In: BAGGIO, Antônio Maria (Org.). O principio esquecido/2. Vargem Grande Paulista, SP: Cidade Nova, 2009. p. 151-173.

CARDOSO, Alenilton da Silva. Princípio da solidariedade: o paradigma ético do direito contemporâneo/Alenilton da Silva Cardoso. - São Paulo: Editora Juarez de Oliveira, 2010.

FARIAS, José Fernando de Castro. A origem do direito de solidariedade/José Fernando de Castro Farias. - Rio de Janeiro: Renovar, 1998.

FERRER, Gabriel Real. Calidad de vida, médio ambiente, sostenibilidad y ciudadanía i construimos juntos el futuro? Novos Estudos Jurídicos, v. 17, n. 3, Dez. 2012. Disponível em: $<$ http://siaiweb06.univali.br/seer/index.php/nej/article/view/4202 > . Acesso em: 02 fev. 2014.

FREITAS, Juarez. Sustentabilidade: direito ao futuro. 2 ed. Belo Horizonte: Fórum, 2012.

IGHINA, Domingo. "Unidos ou dominados". Sobre uma leitura da fraternidade em função latino-americana. In: BAGGIO, Antonio Maria (Org.). O principio esquecido/2. Vargem Grande Paulista, SP: Cidade Nova, 2009. p. 33-42.

MORAES, Maria Celina Bodin de. O Princípio da Solidariedade. Disponível em <http://www.idcivil.com.br/pdf/biblioteca9.pdf>. Acesso em: 21 mar. 2014.

MORIN, Edgard. La vía para el futuro de la humanidad. Traducción de Núria Petit Fontseré. Barcelona: Paidós, 2011. 
PEZZIMENTI, Rocco. Fraternidade: o porquê de um eclipse. In: BAGGIO, Antonio Maria (Org.). O principio esquecido/1. Vargem Grande Paulista, SP: Cidade Nova, 2008. p. 57-76.

SAVAGNONE, Giuseppe. Fraternidade e comunicação, com especial referencia à comunicação jornalística. In: BAGGIO, Antonio Maria (Org.). O principio esquecido/2. Vargem Grande Paulista, SP: Cidade Nova, 2009, p. 195-248.

TOSI, Giuseppe. A fraternidade é uma categoria política? In: BAGGIO, Antonio Maria (Org.). O principio esquecido/2. Vargem Grande Paulista, SP: Cidade Nova, 2009. p. 43-64. 